\title{
Experience of managing open fractures of the lower limb at a major trauma centre
}

\author{
AM Ali, JM McMaster, D Noyes, AJ Brent, LK Cogswell \\ Oxford University Hospitals NHS Trust, UK
}

ABSTRACT

INTRODUCTION In April 2012 the John Radcliffe Hospital in Oxford became a major trauma centre (MTC). The British Orthopaedic Association and British Association of Plastic, Reconstructive and Aesthetic Surgeons joint standards for the management of open fractures of the lower limb (BOAST 4) require system-wide changes in referral practice that may be facilitated by the MTC and its associated major trauma network.

METHODS From 2008 to 2013 a multistep audit of compliance with BOAST 4 was conducted to assess referral patterns, timing of surgery and outcomes (surgical site infection rates), to determine changes following local intervention and the establishment of the MTC.

RESULTS Over the study period, 50 patients had soft tissue cover for an open lower limb fracture and there was a significant increase in the proportion of patients receiving definitive fixation in our centre $(p=0.036)$. The median time from injury to soft tissue cover fell from 6.0 days to 3.5 days $(p=0.051$ ) and the median time from definitive fixation to soft tissue cover fell from 5.0 days to 2.0 days $(p=0.003)$. The deep infection rate fell from $27 \%$ to $8 \%(p=0.247)$. However, in 2013 many patients still experienced a delay of $>72$ hours between injury and soft tissue cover, primarily owing to a lack of capacity for providing soft tissue cover.

CONCLUSIONS Our experience may be relevant to other MTCs seeking to identify barriers to optimising the management of patients with these injuries.

\section{KEYWORDS}

Open fracture - Lower limb - Major trauma centre

Accepted 8 February 2015

CORRESPONDENCE TO

Adam Ali, E: adamali@post.harvard.edu

In September 2009 the British Orthopaedic Association (BOA) and the British Association of Plastic, Reconstructive and Aesthetic Surgeons (BAPRAS) published joint standards for the management of open fractures of the lower limb, which emphasised the importance of early transfer of patients with complex open fractures to a specialist centre. ${ }^{1}$ These enable orthopaedic and plastic surgical teams with experience in managing such injuries to coordinate patient care, minimising delays in surgery and leading to improved outcomes. ${ }^{2,3}$ We performed an audit of referral practice in the one year before and after the introduction of the BOA/BAPRAS guidelines, and found no evidence of change in referral practice in our region.

In 2012 the creation of major trauma centres (MTCs) and their associated major trauma networks (MTNs) streamlined the process of patient transfer. It provided an important opportunity to improve compliance with the BOA/BAPRAS standards and BOA Standards for Trauma (BOAST 4) targets, ${ }^{4}$ in particular minimising the delay between definitive fixation and soft tissue cover, and achieving soft tissue cover within 72 hours of injury.
Our centre is a regional referral centre for orthopaedic trauma and plastic surgery serving a population of 3 million people. In April 2012 it became one of 22 MTCs in England. ${ }^{5}$ Over the last five years, we have audited compliance with the BOA/BAPRAS standards and BOAST 4 so as to identify potential barriers to achieving timely soft tissue cover of open lower limb fractures since delays have been shown to be independently associated with increased risk of related complications such as infection. ${ }^{6}$ This study sought to assess the impact on clinical practice of changes related to the establishment of the MTC/MTN, in particular how these changes have affected the timing and location of surgery as well as the rate of surgical site infection (SSI).

\section{Methods}

Using local databases, all patients undergoing soft tissue cover with flaps for an open fracture of the lower limb in the John Radcliffe Hospital between September 2008 and April 2013 were identified. Those who only required split skin grafting were excluded from the study. In each case, 


\begin{tabular}{lllll|}
\hline $\begin{array}{l}\text { Table } 1 \text { Number of direct and indirect (initial presentation to district general hospital [DGH]) admissions in each time period with } \\
\text { percentage of total number of admissions for that period }\end{array}$ & $\begin{array}{lll}\text { Direct admissions } \\
\text { to our centre }\end{array}$ & $\begin{array}{l}\text { Indirect admissions with } \\
\text { definitive fixation at DGH } \\
\text { Time period }\end{array}$ & $\begin{array}{l}\text { Indirect admissions with } \\
\text { definitive fixation at our centre }\end{array}$ & Total admissions \\
Period 1 (Sep 2008-Sep 2010) & $10(45 \%)$ & $6(27 \%)$ & $6(27 \%)$ & 22 \\
Period 2 (April 2011 - April 2012) & $8(53 \%)$ & $1(7 \%)$ & $6(40 \%)$ & 15 \\
\hline Period 3 (April 2012 - April 2013) & $7(54 \%)$ & $0(0 \%)$ & $6(46 \%)$ & 13 \\
\hline
\end{tabular}

the medical notes were reviewed to extract: patient demographics using a standardised proforma; injury sustained (with fractures being classified according to the GustiloAnderson system); the type, timing and location of treatment provided (and therefore the time from injury to soft tissue cover as well as from definitive fixation to soft tissue cover); and the occurrence of SSIs, which we classified using the Centers for Disease Control and Prevention criteria (Appendix 1 - available online). ${ }^{7}$

Cases were reviewed in April 2014, giving a follow-up period for all cases of at least one year. The causes of delayed soft tissue cover were classified as one or a combination of: i) delays in transfer to our centre from a district general hospital (DGH); ii) the patient being unfit for surgery; iii) delay in definitive fixation; and iv) delay between definitive fixation and soft tissue cover. Performance was compared across three periods:

\section{Period 1 (September 2008 - September 2010):}

This represents the year before and after publication of the BOA/BAPRAS standards in September 2009, between which times there was no change in referral practice. Audit data from this period were fed back locally and to our referring DGHs between September 2010 and April 2011, following which changes were implemented to improve referral practice, in particular: stressing the need for referral of patients with complex open fractures to our centre as soon as possible and before definitive fixation is performed; and implementation of an orthoplastic protocol designed to reinforce the BOA/BAPRAS guidelines, and minimise delay between definitive fixation and soft tissue coverage.

Period 2 (April 2011 - April 2012):

Analysis of period 2 allowed assessment of the impact of changes made following the audit of practice in period 1.

\section{Period 3 (April 2012 - April 2013):}

This final period covers the year following establishment of our centre as a MTC in April 2012.

Trends in proportions and in the interval between procedures across each of these analysis periods were assessed using the chi-squared test for trend and the Mann-Whitney $\mathrm{U}$ test respectively.

\section{Results}

Between September 2008 and April 2013, 50 patients had soft tissue flap cover for an open fracture of the lower limb
(Table 1). The median age at the time of injury was 38 years (range: $11-79$ years, interquartile range: $22-53$ years). Most were classified as Gustilo type IIIB $(n=38)$; the remainder were type IIIC $(n=4)$ or type III unspecified $(n=8)$. Road traffic accidents accounted for most injuries (32 cases, including 20 motorcyclists and 8 pedestrians), followed by falls (15 cases); two patients were injured while playing football and another after being kicked by a horse. Soft tissue coverage comprised a free flap in 46 cases $(92 \%$; 27 gracilis, 17 latissimus dorsi, 2 latissimus dorsi/serratus anterior chimeric) and a local flap in 4 cases $(8 \%)$.

Over the study period, there was a significant increase in the proportion of patients who received definitive fixation at the MTC rather than their local DGH, with all patients in period 3 receiving definitive fixation at the MTC (chisquared test for trend, $p=0.036$; Table 1). Paralleling this was a trend towards shorter intervals between injury and soft tissue cover from a median of 6.0 days to 3.5 days (Fig 1; $p=0.051$ ). The median time from definitive fixation to soft tissue cover fell from 5.0 days to 2.0 days ( $\mathrm{Fig} 2 ; p=0.003$ ).

The proportion of patients who developed a SSI fell progressively, with deep infection rates of $27 \%$ in period 1 and $8 \%$ in period 3 ( $p=0.247$; Table 2 ; Fig 3 ). Seven other patients required a further procedure owing to flap related complications: five patients required debridement of necrotic flap tissue, one patient required reanastomosis following flap failure and one patient, who had sustained a Gustilo type IIIC compound fracture dislocation of the ankle requiring arterial grafting, subtotal amputation of the foot and a latissimus dorsi/serratus anterior chimeric flap sited on day 13 following the injury, went on to have a below-knee amputation on day 20 owing to vascular compromise.

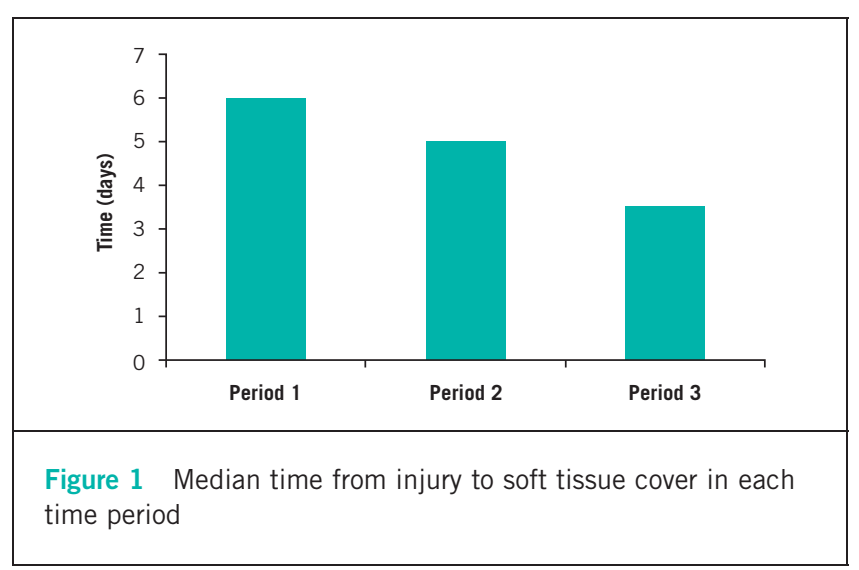




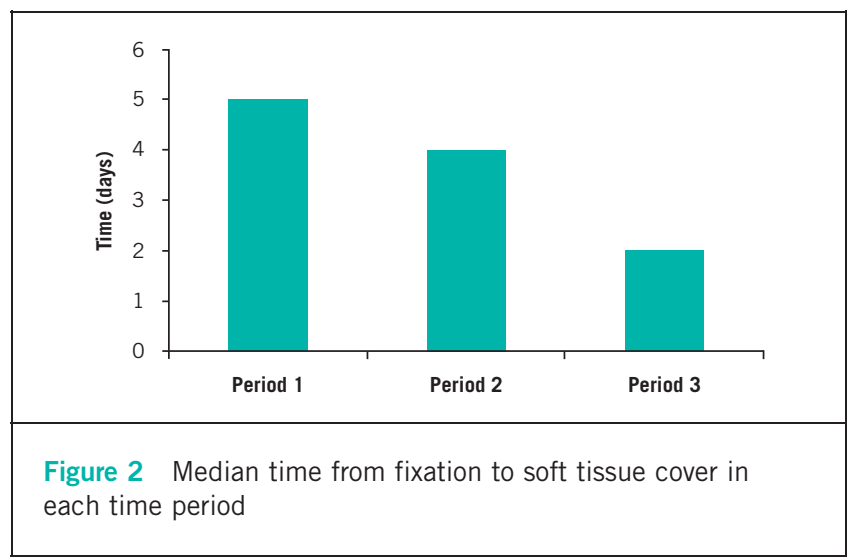

\section{Outcomes achieved following major trauma centre formation}

Since our centre became a MTC in April 2012, all patients had initial skeletal stabilisation (external or internal fixation) within 24 hours of injury; 5 out of 13 patients had an interval from injury to definitive fixation of $<24$ hours and from injury to soft tissue cover of $<72$ hours (i.e. met the BOAST 4 target) while the remaining 8 had an interval from injury to soft tissue cover of $>72$ hours (Table 3).

Reasons were explored for the delay among the eight patients who did not receive soft tissue cover until $>72$ hours after their injury. These included delay in transfer to the MTC from the DGH (2 cases), the need to stabilise the patient medically prior to surgery ( 2 cases) and delay in soft tissue cover due to lack of surgical and/or theatre capacity for a free flap procedure (7 cases). One of the aims of our orthoplastic protocol was to minimise the time between definitive fixation and soft tissue cover. In three cases, definitive fixation was performed at $>72$ hours after injury, when it was anticipated that soft tissue coverage would be delayed.

\section{Discussion}

This paper reports on all cases of open lower limb fractures that required soft tissue coverage in our centre from September 2008 to April 2013. There was no significant change in the total number of cases before and after formation of the MTC in April 2012. This is most likely due to the fact that

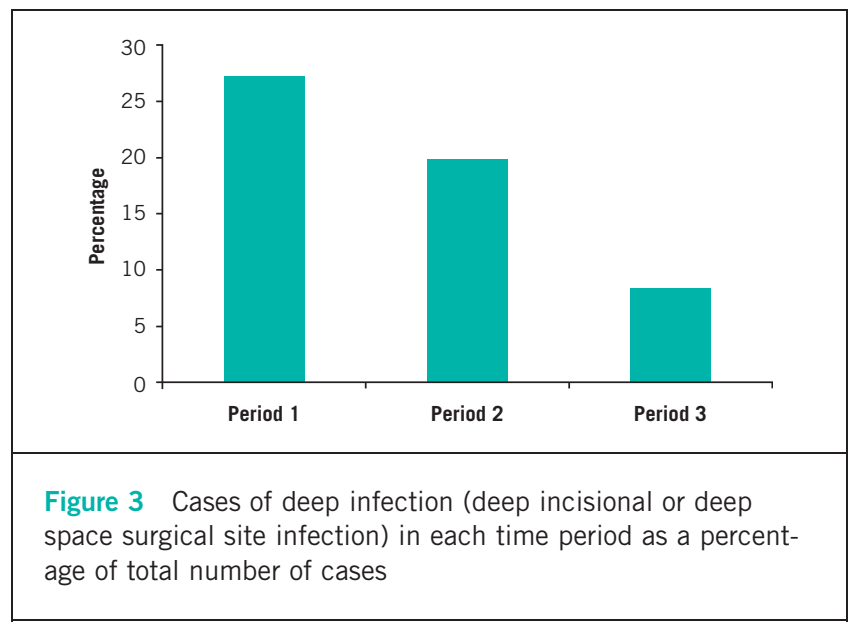

prior to MTC formation, our centre served as the regional plastic surgery referral centre for the same population and therefore already received referrals for complex reconstructive surgery such as that often needed for open lower limb fractures. Indeed, the majority of cases seen were Gustilo type IIIB (extensive soft tissue injury with periosteal stripping and bone exposure) and $92 \%$ needed free flaps requiring specialist surgery available in our centre.

Shorter intervals from injury to definitive fixation and from injury to soft tissue cover are associated with improved outcomes. ${ }^{3}$ This is facilitated by having definitive fixation performed in the specialist centre. In period 1 , $50 \%$ of patients who were indirect admissions had definitive fixation performed at a DGH. This compromised the ability to perform further debridement and increased the time in which patients had exposed metalwork in situ. The median time from definitive fixation to soft tissue cover was 5 days. Following communication with other centres, practice improved. In the following year, prior to the structural changes imposed by the MTC, only $14 \%$ of indirect admissions received definitive fixation at a DGH. In the year following MTC formation, all patients had definitive fixation in our centre.

Across the three time periods, there was a substantial and significant decrease in the interval from fixation to soft tissue cover $(p=0.003)$ and a substantial decrease in the time from injury to soft tissue cover $(p=0.051)$. However, in

Table 2 Number of cases in each time period that subsequently developed a surgical site infection (SSI), classified according to Center for Disease Control and Prevention criteria ${ }^{7}$

\begin{tabular}{|llllll|} 
Time period & $\begin{array}{l}\text { Total number } \\
\text { of patients }\end{array}$ & $\begin{array}{l}\text { Superficial } \\
\text { SSIs }\end{array}$ & $\begin{array}{l}\text { Deep incisional } \\
\text { SSIs }\end{array}$ & $\begin{array}{l}\text { Deep space } \\
\text { SSIs }\end{array}$ & $\begin{array}{l}\text { Total number } \\
\text { of SSIs }\end{array}$ \\
\hline Period 1 (Sep 2008 - Sep 2010) & 22 & $0(0 \%)$ & $1(5 \%)$ & $5(23 \%)$ & $6(27 \%)$ \\
Period 2 (April 2011 - April 2012) & 15 & $0(0 \%)$ & $0(0 \%)$ & $3(20 \%)$ & $3(20 \%)$ \\
Period 3 (April 2012 - April 2013) & 13 & $1(8 \%)$ & $0(0 \%)$ & $1(8 \%)$ & $2(15 \%)$ \\
\hline
\end{tabular}


the most recent period, the median time between fixation and soft tissue cover remained 2.5 days, and in $62 \%$ of cases, the delay from injury to soft tissue cover exceeded 72 hours and so failed to meet the BOAST 4 targets. Patients are therefore being transferred to our centre more quickly following the introduction of the MTC, as has been shown elsewhere, ${ }^{2}$ and are having definitive fixation performed in our centre but there remained a delay in achieving soft tissue cover in period 3.

The fall in the deep infection rate may reflect reduced time to surgery. ${ }^{6}$ Nevertheless, small numbers limit the power of our analysis so this may have occurred by chance and other factors that may have affected the infection rate were not assessed.

Analysis of cases where the time from injury to soft tissue cover exceeded 72 hours revealed that the primary reason for this was a lack of capacity for soft tissue cover. This is an issue we have since addressed with the appointment of further plastic surgery consultants who participate in a trauma rota providing a free flap service. Measures have also been introduced to overcome the structural constraints of our hospital as orthopaedic trauma and plastic surgery services are located in different theatres. The orthopaedic trauma theatres now have an operating microscope and primary 'fix and flap' cases are being performed (where logistically possible). This approach has been shown to be associated with superior outcomes including reduced infection rates. ${ }^{8,9}$ The complexity of the orthopaedic inventory required determines which theatre is used to perform these cases.

\section{Conclusions}

The formation of MTCs has facilitated early, combined orthoplastic assessment of open lower limb fractures by surgeons familiar with managing such injuries, and a reduction in the time to fixation and definitive soft tissue coverage; this has been associated with improved outcomes. ${ }^{2,3,8,10,11}$ However, there remains scope for expediting definitive soft tissue coverage both in our centre and in other MTCs through a process determined by local structural constraints. ${ }^{12}$ The 'fix and flap' protocol is regarded as the gold standard for treatment. On the other hand, as the BOA/BAPRAS guidelines highlight, it may be best suited to cases requiring local flaps. Patients requiring free tissue transfer may need additional investigation and preparation prior to surgery, which should be performed in elective conditions by dedicated senior surgeons. ${ }^{1}$

\section{References}

1. Nanchahal J, Nayagam S, Khan U et al. Standards for the Management of Open Fractures of the Lower Limb. London: BAPRAS; 2009.

2. Stammers J, Williams $D$, Hunter Jet al. The impact of trauma centre designation on open tibial fracture management. Ann R Coll Surg Engl 2013; 95: 184187.

3. Mackenzie EJ, Rivara FP, Jurkovich GJ et al. The impact of trauma-center care on functional outcomes following major lower-limb trauma. J Bone Joint Surg Am 2008; 90: 101-109.

4. British Orthopaedic Association; British Association of Plastic, Reconstructive and Aesthetic Surgeons. BOAST 4: The Management of Severe Open Lower Limb Fractures. London: BOA; 2009.

5. Major trauma centres to open across England. GOV.UK. http://www. gov.uk/ government/news/major-trauma-centres-to-open-across-england (cited March 2015).

6. D'Alleyrand JC, Manson TT, Dancy L et al. Is time to flap coverage of open tibial fractures an independent predictor of flap-related complications? J Orthop Trauma 2014; 28: 288-293.

7. Horan TC, Gaynes RP, Martone WJ et al. CDC definitions of nosocomial surgical site infections, 1992: a modification of CDC definitions of surgical wound infections. Am J Infect Control 1992; 20: 271-274.

8. Gopal S, Majumder S, Batchelor AG et al. Fix and flap: the radial orthopaedic and plastic treatment of severe open fractures of the tibia. $J$ Bone Joint Surg $B r$ 2000; 82: 959-966.

9. Hertel R, Lambert SM, Müller S et al. On the timing of soft-tissue reconstruction for open fractures of the lower leg. Arch Orthop Trauma Surg 1999; 119: 7-12.

10. Nayagam S, Graham K, Pearse M, Nanchahal J. Reconstructive surgery in limbs: the case for the orthoplastic approach. Ann Plast Surg 2011; 66: 6-8.

11. Naique SB, Pearse M, Nanchahal J. Management of severe open tibial fractures. J Bone Joint Surg Br 2006; 88: 351-357.

12. Yarrow J, Rahman S, Marsden Net al. Management of open lower limb injuries in South West England and Wales. Ann R Coll Surg Engl 2015; 97: 35-39. 